\title{
Perspetivas interdisciplinares sobre consumo e crédito
}

Ana Cordeiro Santos, Catarina Frade e Miguel Oliveira

\section{OpenEdition}

\section{Journals}

Edição electrónica

URL: http://journals.openedition.org/rccs/5336

DOI: $10.4000 /$ rccs.5336

ISSN: 2182-7435

\section{Editora}

Centro de Estudos Sociais da Universidade de Coimbra

Edição impressa

Data de publição: 1 setembro 2013

Paginação: 03-08

ISSN: 0254-1106

\section{Refêrencia eletrónica}

Ana Cordeiro Santos, Catarina Frade e Miguel Oliveira, «Perspetivas interdisciplinares sobre consumo e crédito», Revista Crítica de Ciências Sociais [Online], 101 | 2013, posto online no dia 17 fevereiro 2014 consultado o 04 fevereiro 2021. URL: http://journals.openedition.org/rccs/5336 ; DOI: https://doi.org/ $10.4000 /$ rccs. 5336

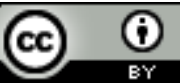




\section{Perspetivas interdisciplinares sobre consumo e crédito}

Nunca como nos dias que correm se discutiu, na academia ou na esfera pública, o consumo, o endividamento e a insolvência das famílias portuguesas. Esta discussão não pode ser desligada do contexto de grave crise económica que o país atravessa, que se atribui a elevadas taxas de endividamento, privado e público, e a politicas de austeridade que vêm sendo implementadas para lhe dar resposta, mas que não fazem mais do que agravar os seus efeitos.

No entanto, a expansão do consumo e o crescimento do endividamento das famílias são fenómenos partilhados pelas economias capitalistas mais avançadas, fazendo parte de um processo mais vasto de extraordinário crescimento do setor financeiro, conbecido na literatura crítica por financeirização (Epstein, 2005; Barba e Pivetti, 2009). Resultado de politicas neoliberais de privatização dos bancos, de abolição dos controlos de capitais e de desregulamentação dos mercados financeiros, este processo promoveu uma crescente imbricação das economias, dos Estados, das empresas e das famílias com a finança, sendo o endividamento uma das suas variadas manifestações. O endividamento das famílias portuguesas deve-se, em particular, a uma política europeia de liberalização dos mercados monetários e financeiros nacionais com vista à criação de uma união monetária, da qual Portugal fez parte desde o início, e que tornou o crédito mais acessivel para as famílias portuguesas, embora apenas $40 \%$ destas detenham algum tipo de divida (Reis et al., 2013; Santos e Costa, 2013). Foi com a crise e com a recessão económica prolongada que o seu endividamento se tornou um grave problema económico e social.

Sendo certo que o endividamento das famílias portuguesas cresceu a um ritmo acelerado ao longo das duas últimas décadas, este esteve sempre associado a niveis baixos de incumprimento, mesmo tomando como referência o contexto europeu (Lopes e Frade, 2012). As maiores dificuldades começaram a sentir-se com as medidas de austeridade geradoras de desemprego, promotoras de cortes salariais no setor público e de aumento da carga fiscal sobre a generalidade dos trabalhadores, refletindo-se no crédito mal parado nas carteiras dos bancos e no crescimento sem precedentes da taxa de insolvência de particulares, que espelham bem a degradação acelerada das condições de vida de segmentos importantes da população portuguesa (Leaby et al., 2013). 
Quer isto dizer que a análise do endividamento das famílias não pode descurar o contexto macroeconómico que determina a capacidade financeira destas de proverem às suas necessidades mais elementares. Também não pode ignorar importantes transformações sociais que enquadram as decisões de consumo e de crédito das famílias, que são frequentemente desconsideradas em análises apressadas e discursos moralistas tendenciosos, que responsabilizam as familias pela grave situação do país, acusando-as de terem adotado um padrão de consumo acima das suas possibilidades (Santos, 2013).

O presente número temático reúne diversas contribuições sobre o consumo e o crédito, identificando os múltiplos fatores, bem como as complexas interações que se estabelecem, e que, em conjunto, determinam estes relevantes comportamentos socioeconómicos. A multidimensionalidade do consumo e do crédito está bem patente no interesse que têm suscitado nos mais variados campos de pesquisa. O consumo e o crédito oferecem leituras mais ou menos complementares, mais ou menos rivais sobre estes temas. Contudo, as tentativas de diálogo entre as diferentes abordagens são ainda escassas, observando-se um relativo isolamento das diversas áreas de saber. Nesta medida, o presente número temático procura dar mais um passo em direção ao estabelecimento deste diálogo, reunindo os contributos de vários cientistas sociais que se têm dedicado ao estudo do consumo e do crédito em Portugal.

Oprimeiro artigo, de Ana C. Santos, Vânia Costa $e$ Nuno Teles, oferece uma revisão crítica dos principais contributos da economia, psicologia e sociologia, sublinhando como os diálogos interdisciplinares dependem da convergência de interesses das várias áreas disciplinares, sendo determinantes na apropriação seletiva e no aproveitamento que se faz dos recursos oriundos de outras proveniências, o que evita comprometer os cânones vigentes. Propõe uma análise interdisciplinar do consumo e do crédito, ancorada na tradição da economia política. Esta dá especial relevância a fatores estruturais, como transformações recentes do capitalismo contemporâneo que se traduziram num extraordinário crescimento do peso do poder económico e político da finança, e sublinha mudanças sociais relevantes, como a crescente dominação da ideologia neoliberal, que promove uma individualização da provisão de bens e serviços favorável ao setor financeiro. A consideração do contexto social e político impede a atribuição do essencial das dificuldades financeiras das familias a escolhas desinformadas e equivocadas dos consumidores, nomeadamente a erros de apreciação do risco associado ao crédito ou ao investimento financeiro. Situa-as, pelo contrário, na quebra de rendimentos, no crescimento das desigualdades sociais, na perda de direitos laborais e sociais, bem como na vulnerabilidade decorrente da própria financeirização das famílias, cujas despesas e rendimentos dependem cada vez mais do funcionamento volátil dos mercados financeiros. 
Mesmo a psicologia, centrando-se nos processos de decisão individual, admite a sua contingência face ao contexto, o qual tende a acionar mecanismos mais ou menos adaptados à situação. Miguel Oliveira $e$ Fernanda Jesus frisam que a incerteza inerente às decisões de crédito introduz um nivel adicional de complexidade no processo de decisão que vai para lá da mera escolha de produtos alternativos de acordo com preferências predeterminadas. Uma característica distintiva do crédito diz respeito à separação temporal entre o ato de consumo $e$ $o$ ato de pagamento, que distingue a compra a crédito de uma compra a pronto. A natureza intertemporal do crédito introduz incerteza e risco na exata medida em que o adiamento do pagamento complica a consideração de necessidades e rendimentos futuros no cálculo. O que significa que a incerteza inerente ao crédito, bem como a complexidade dos próprios produtos financeiros, que nada tem de natural, põem em causa explicações que reduzem a existência de dificuldades financeiras a escolhas desinformadas e equivocadas. No entanto, a antecipação do consumo que o acesso ao crédito possibilita, transformando a possibilidade de aquisição em algo certo, pode contribuir para a desvalorização da incerteza associada ao escalonamento do pagamento ao longo do tempo. Por outro lado, a sobrecarga cognitiva que a incerteza introduz no processo de decisão pode potenciar um funcionamento psicológico e comportamental instável em que confluem elementos cognitivos, emocionais e de autocontrolo da ação que visam lidar com a complexidade e o conflito na decisão. Estas características intrinsecas ao crédito podem ser exploradas pela publicidade e pelo marketing, que, por via do enquadramento da decisão que promovem, potenciam um funcionamento psicológico que com grande probabilidade reforça avaliações afetivas associadas ao consumo, inibidoras de um julgamento e uma consideração das respetivas alternativas e consequências, como o adiamento do consumo através da poupança. Quer isto dizer que o processo de construção de preferências e atitudes face ao crédito depende de elementos diversos presentes no contexto de decisão, também eles decisivamente integrantes de tais preferências e atitudes, apesar de não totalmente controláveis pelo indivíduo.

Ainda que concedendo espaço à agência bumana, a perspetiva sociológica sobre o consumo e o crédito tem naturalmente presente que as escolbas de consumo são socialmente condicionadas por processos complexos que geram as suas próprias normas e para os quais concorrem uma multiplicidade de atores, com interesses mais ou menos conflituantes, desde a família, aos média, passando pela própria finança. Entre outros, estes processos incluem a transmissão intergeracional de atitudes e comportamentos, a influência de estratégias de marketing e publicidade, a que já se aludiu acima, bem como as politicas sociais e de defesa do consumidor. É este condicionalismo social que explica a importância da socialização nos hábitos e padrões de consumo, 
como notam Raquel Barbosa Ribeiro, Susana Albuquerque, Jaime Raúl Seixas Fonseca, Carlos Bicho Pires $e$ Diana Rodrigues Quintino. O consumo é, nesta ótica, associado a representações sociais, transmitidas através de processos de socialização para o consumo, e à apropriação que delas é feita pelos individuos, em que confluem um emaranhado de normas, valores, crenças, atitudes, representações e práticas, num processo eminentemente moral de reprodução e transmissão culturais. Significa isto que, para lá da satisfação de necessidades meramente utilitárias, os consumidores também procuram corresponder a normas de aceitação, prestígio e conformidade social, reproduzir práticas enraizadas nos seus hábitos e, em alguns casos, inclusivamente adaptar de forma criativa estas normas à definição de um estilo de vida próprio. Assim, e em claro contraste com o discurso legitimador da economia convencional, que vê o consumo e o crédito como pertencendo ao foro estrito do individuo, a sociologia adota uma perspetiva mais crítica, associando-o à manipulação, ao impulso e à emotividade, enfatizando a carga moral e política do mesmo.

As decisões de consumo não são única e exclusivamente marcadas por normas e representações sociais sobre este. Lina Coelho defende que aquelas são também afetadas por representações sobre o casamento e o género, as quais influenciam a partilh a de recursos materiais dentro da família e, por esta via, as relações de poder e a distribuição do bem-estar pelos seus membros. Argumenta, em particular, que as representações sociais sobre género e casamento, ao influenciarem comportamentos de homens e mulheres, podem favorecer práticas que reforçam ou atenuam a conversão do acesso a recursos que, em geral, são assimetricamente distribuídos entre homens e mulheres em poder efetivo no seio da família. Chama, assim, a atenção para o facto de as decisões de consumo e crédito serem muitas vezes tomadas no contexto familiar, obedecendo a lógicas de cooperação e partilha, mas envolvendo também a negociação entre os seus membros. A complexidade destes fenómenos mostra bem quão desadequada e redutora é uma grelha analítica que concebe os atos de consumo como meros atos de satisfação de preferências individuais. Estes são, pelo contrário, o resultado de interações complexas, onde figuram diversas perceções relativas ao bem-estar, que podem ser mais ou menos convergentes, e as contribuições e pretensões de cada membro da família, também elas diferenciadas e equacionadas naquelas decisões.

Ao falar-se de representações sociais não pode deixar de se destacar o papel dos média na disseminação de representações sociais sobre o consumo e o crédito, bem como sobre o casamento e o género, entre outras. Centrando-se na literatura de autoajuda financeira, Fernando Ampudia de Haro chama a atenção para o facto de que no atual contexto de financeirização e de domínio da ideologia neoliberal é cada vez mais veiculada a ideia de responsabilização individual, 
culpabilizando o consumidor e delegando nele a saída para crise. Em consonância com a visão da economia convencional, estas explicações partem dessa culpabilização, cujas práticas de consumo e de endividamento conduziram à situação de sobre-endividamento nacional, para avançarem com soluções também elas individuais que passam pela aprendizagem da responsabilidade financeira. Faz-se assim o elogio à autorresponsabilização, tomando a insegurança e a incerteza, que reconhecidamente subjazem à decisões financeiras, como valores que fomentam e promovem a autonomia individual. Ao mesmo tempo que promove a responsabilização individual, este género de literatura também deslegitima formas de governação coletivas, como o Estado social, considerando-as fracassadas e potenciadoras de irresponsabilidade individual, com efeitos coletivos perversos. Fica, assim, claro que o autogoverno responsável que se preconiza é para ser exercido no mercado, alimentando o peso económico e político da finança. Os vagos conselhos de investimento financeiro distinguem-se, pois, das tradicionais noções de poupança. O investimento comporta incerteza e risco, que são entendidos como uma oportunidade de geração de novo rendimento, senão mesmo de enriquecimento fácil, que cada um deve aproveitar, aceitando, ao mesmo tempo, as suas consequências caso o investimento não produza os resultados esperados.

Este discurso penalizador, moralista e centrado no indivíduo está também presente no direito falimentar, que promove uma cultura estigmatizante em torno daqueles que, por incapacidade de pagar as suas dividas, encontram na falência uma solução de último recurso. É disto que nos dão conta Catarina Frade $e$ Ana Filipa Conceição quando argumentam que hoje, como no passado, a falência é sempre encarada como uma solução que, apesar de economicamente necessária, é incómoda e inaceitável do ponto de vista social, moral e até jurídico. O repúdio sentido pelos falidos, acusados de não se aterem à norma social vigente que pressupõe a honorabilidade dos contratos, foi expresso através de um quadro sancionatório que associava à perda da vida ou do património aviltamentos, opróbrio e humilhações variadas. Essa atitude negativa face aos falidos transitou para os direitos falimentares contemporâneos, apesar de cada vez mais se admitir que o risco pelo insucesso financeiro terá de ser partilhado pelos credores e não apenas suportado pelos devedores, sobretudo quando se trata de famílias.

Ana Cordeiro Santos

Catarina Frade

Miguel Oliveira 


\section{Referências bibliográficas}

Barba, A.; Pivetti, M. (2009), "Rising Household Debt: Its Causes and Macroeconomic Implications - A Long-period Analysis”, Cambridge Journal of Economics, 33, 113-137.

Epstein, G. (org.) (2005), Financialization and the World Economy. Northampton: Edward Elgar Press.

Leahy, A.; Healy, S.; Murphy, M. (2013), The Impact of the European Crisis: A Study of the Impact of the European Crisis and Austerity on People with a Special Focus on Greece, Ireland, Italy, Portugal and Spain. Caritas Europa.

Lopes, C. A.; Frade, C. (2012), "The Way into Bankruptcy: Market Anomie and Sacrifice among Portuguese Consumers”, Journal of Consumer Policy, 35, 477-496.

Reis, J.; Rodrigues, J.; Santos, A.; Teles, N. (2013), "Compreender a crise: A economia portuguesa num quadro europeu desfavorável”, in J. Reis (org.), A anatomia da crise: Identificar os problemas para construir as alternativas. Primeiro relatório preliminar do Observatório sobre Crises e Alternativas, 12-71.

Santos, A. C.; Costa, V. (2013), "Regular o consumidor? Novas tendências de política no sector financeiro”, Análise Social, XLVIII(209), 756-790.

Santos, A. C. (2013), “Temos vivido acima das nossas possibilidades?”, in José Soeiro; Miguel Cardina e Nuno Serra (orgs.), Não acredite em tudo o que pensa. Lisboa: Tinta da China, 17-29. 